\title{
A single-center retrospective study of pediatric hepatoblastoma
}

\author{
YI ZHANG ${ }^{1,2^{*}}$, WEILING ZHANG $^{1 *}$, SUOQIN TANG $^{2}$, LIPING CHEN $^{1}$, YOU YI ${ }^{1}$, \\ PINWEI ZHANG ${ }^{1}$, AIPING LIU ${ }^{1}$, TIAN ZHI ${ }^{1}$ and DONGSHENG HUANG ${ }^{1}$ \\ ${ }^{1}$ Department of Pediatrics, Beijing Tongren Hospital, Capital Medical University, Beijing 100176; \\ ${ }^{2}$ Department of Pediatrics, People's Liberation Army General Hospital, Beijing 100853, P.R. China
}

Received June 10, 2015; Accepted August 26, 2016

DOI: $10.3892 / 01.2016 .5195$

\begin{abstract}
Hepatoblastoma is a malignant liver tumor generally diagnosed in infants and children $<3$ years old. The current retrospective study aimed to investigate the associations of tumor stage, pathological type, metastasis and chemotherapy with clinical outcomes. In the current study, a total of 102 patients with hepatoblastoma were enrolled between September 2006 and June 2014. Clinical records and follow-up information for each of patient were obtained to conduct a Kaplan-Meier survival analysis and log-rank test. The median age of the subjects was 1.5 years, and 98 patients had stage III or IV hepatoblastoma. Complete or partial remittance occurred in 72 subjects, and 91 underwent surgical operation. The survival rate differed significantly among patients with different tumor stages $\left(\mathrm{P}=0.015, \chi^{2}=8.359\right)$. The mortality rate of stage IV subjects with intrahepatic metastasis was significantly higher than that of those without $(\mathrm{P}=0.004)$. Among the 45 subjects with relapsed hepatoblastoma, the mortality rate was higher in the subjects that abandoned chemotherapy than in patients who continued regular chemotherapy. In total, 27 of 45 subjects with relapsed hepatoblastoma succumbed to the disease; 20 of them abandoned chemotherapy treatment; and the remaining 7 patients underwent regular chemotherapy and succumbed to the disease by the end of follow-up. The present study indicates that the increased mortality rate was associated with postoperative residual-induced intrahepatic metastasis and relapsed hepatoblastoma; and that regular chemotherapy is necessary for patient to achieve complete or partial remission following surgical operation.
\end{abstract}

Correspondence to: Professor Dongsheng Huang, Department of Pediatrics, Beijing Tongren Hospital, Capital Medical University, 2 Chongwenmennei Street, Dongcheng, Beijing 100176, P.R. China E-mail: dongshenghuang99@163.com

*Contributed equally

Key words: pediatric hapatoblastoma, surgical operation, chemotherapy, prognosis, survival rate

\section{Introduction}

Hepatoblastoma is a highly malignant common primary liver tumor generally observed in infants and children $<3$ years old (1). Hepatoblastoma is the third most common abdominal neoplasm in this age group after neuroblastoma and nephroblastoma (2), and comprises $25-45 \%$ of all liver tumors and nearly $60 \%$ of all primary malignant tumors of the liver during childhood, posing a serious threat to health in the early stages of life. The incidence of hepatoblastoma is 1.5 times higher in males than in females (3). The morbidity rate was $1.2-1.7 /$ million in the late 1990s in Europe, and may still be decreasing (3-5).

Recent innovations in treatment have significantly increased the survival rate of patients with hepatoblastoma during the past few decades (6). Before the 1970s, the major method of treating hepatoblastoma was hepatectomy without the application of effective post-surgical chemotherapy, resulting in a low survival rate of $20-30 \%$ for patients (7). Since the 1980s, however, chemotherapy with platinum-based anticancer drugs has been used and the 5-year survival rate of patients with hepatoblastoma has increased to $\geq 75 \%(8,9)$. Currently, the primary method of treating hepatoblastoma employs systemic chemotherapy (including pre-surgical volume reduction and postoperative chemotherapy), local interventional chemotherapy and high-dose chemotherapy in combination with autologous peripheral blood stem cell transplantation (APBSCT) (10). However, despite the wide application of various chemotherapy measures, the 5-year survival rate for advanced hepatoblastoma remains low, particularly for subjects with metastatic tumors in distant tissues or organs (11).

In order to identify the risk factors affecting disease prognosis and outcome, a single-center retrospective analysis was conducted on 102 subjects with advanced stages of hepatoblastoma collected between September 2006 and June 2014 . The present study aimed to identify appropriate treatment for such subjects, and thus increase the survival rate of patients with advanced hepatoblastoma.

\section{Patients and methods}

Patients. Information on 102 patients, including 55 males and 47 females, was collected by Beijing Tongren Hospital (Beijing, China) between September 2006 and June 2014. These subjects 
were diagnosed to have pediatric hepatoblastoma based on results from pathobiology and iconography analyses. Prior to surgical operation, subjects were categorized into different clinical stages according to the pretreatment extension of disease (PRETEXT) system adopted by the International Childhood Liver Tumors Strategy Group (SIOPEL) (12). Following surgical operation, subjects were recategorized as stage I, II, III or IV based on the malignancy of the hepatoblastoma, according to the Children's Oncology Group (COG) staging criteria (13). Additionally, the hepatoblastoma tumor tissues removed from these subjects were grouped based on pathology as epithelial (including embryonal and fetal subtypes), macrotrabecular or mixed type (14). The detailed categorization and clinical diagnoses of the patients are presented in Table I. The current study was approved by the Committee on Human Study of the Chinese People's Liberation Army General Hospital (Beijing, China) and the Ethics Review Committee of Beijing Tongren Hospital. All procedures involving human participants were in accordance with the 1964 Declaration of Helsinki and its later amendments. Written informed consent was provided by the parents or guardians of the patients.

Treatment. A total of 91 subjects were treated by surgical operation; the remaining 11 patients were unable to undergo surgical operation due to the accelerated malignancy of hepatoblastoma or other reasons (Table I).

For subjects with stage III hepatoblastoma, interventional therapy or surgical operation was conducted following iconographical and serological evaluation. Following surgery, patients underwent 6-9 cycles of chemotherapy. For stage IV subjects with solely intrahepatic metastasis, pre-surgical chemotherapy was adopted for 2-4 cycles. Iconographical and serological evaluation was conducted every 2 cycles. Following surgery, chemotherapy was sustained for 9 cycles.

Pre-surgical volume reduction, local interventional chemotherapy, radiofrequency ablation, and/or minimally invasive surgery were performed following surgical evaluation of the disease. For stage III and stage IV subjects with solely intrahepatic metastasis, liver transplantation was performed following tumor volume reduction induced by 2-4 cycles of pre-surgical chemotherapy or radiofrequency ablation.

Pre-surgical chemotherapy consisted of $90 \mathrm{mg} / \mathrm{m}^{2}$ cisplatin on day $1,1.5 \mathrm{mg} / \mathrm{m}^{2}$ vincristine on day 2 and $600 \mathrm{mg} / \mathrm{m}^{2}$ fluorouracil on day 2, and was sustained for 2-4 cycles. Post-surgical chemotherapy consisted of the AEP method (90 $\mathrm{mg} / \mathrm{m}^{2}$ cisplatin on day $1,25 \mathrm{mg} / \mathrm{m}^{2}$ pirarubicin on days 1-3 and $100 \mathrm{mg} / \mathrm{m}^{2}$ etoposide on days 1-4) and the ACP method $\left(90 \mathrm{mg} / \mathrm{m}^{2}\right.$ cisplatin on day $1,25 \mathrm{mg} / \mathrm{m}^{2}$ pirarubicin on days $1-3$ and $800-1,000 \mathrm{mg} / \mathrm{m}^{2}$ cyclophosphamide on day $1)$, alternately. Post-surgical chemotherapy was sustained for 4-6 cycles.

In order to remove the postoperative residual, the IEA method of chemotherapy treatment $\left(300 \mathrm{mg} / \mathrm{m}^{2}\right.$ ifosfamide on days 1 - 2, $400 \mathrm{mg} / \mathrm{m}^{2}$ carboplatin on day $3,25 \mathrm{mg} / \mathrm{m}^{2}$ pirarubicin on days $4-5$ and $100 \mathrm{mg} / \mathrm{m}^{2}$ etoposide on days $1-5$ ) was applied and repeated for 6-8 cycles.

Follow-up. Follow-up was conducted monthly until August 1, 2014. Subjects were regarded as censored if they abandoned the treatment or were uncontactable.
Statistical analysis. Data were expressed as the mean \pm standard deviation. Normally distributed data were compared using the $t$ test. The $\chi^{2}$ test was used to compare the number of patients. Comparison of data that did not follow a normal distribution was performed according to the Mantel-Cox log-rank test. Kaplan-Meier analysis was used for survival analysis. SPSS software version 19.0 (IBM, SPSS, Armonk, NY, USA) was used for statsitical analysis. $\mathrm{P}<0.05$ was considered to indicate a statistically significant difference.

\section{Results}

Patient clinical features. The median age of the 102 subjects was 1.5 years (range, 1 month-15 years, Fig. 1). The majority of subjects were $<3$ years old. Upon first diagnosis, 74 subjects (72.5\%) had developed an abdominal mass; 10 subjects $(9.8 \%)$ had abdominal pain, fever and jaundice; 11 subjects (10.8\%) had anorexia and weight loss; and 6(5.9\%) had fever and cough. Interestingly, 1 case of hepatoblastoma was detected during a physical examination performed during the pregnancy of the patient's mother.

Application of surgical operations and chemotherapy. Surgical resection of primary hepatoblastoma was conducted for 92 out of the 102 subjects. Radiofrequency ablation was performed to reduce the size of the tumor for 3 patients with primary hepatoblastoma and 1 patient with metastatic tumor. Minimally invasive surgical resection of a metastatic tumor located at the lung was performed for 1 subject.

Pre-surgical chemotherapy was applied to 72 subjects (71.3\%), and the mean number of chemotherapy cycles performed was $2.97 \pm 1.69$ (range, 1-8; median, 3 cycles). Out of the patients undergoing pre-surgical chemotherapy, pre-liver-puncture chemotherapy was conducted for 68 subjects $(67.3 \%)$, and post-liver-puncture chemotherapy was conducted for 4 subjects (4.0\%). Post-surgical chemotherapy was administered to 86 patients $(84.3 \%)$, and the mean number of cycles performed was 8.50 55.23 (range, 4-32; median, 7 cycles).

Pre-surgical interventional therapy was received by 17 patients. The average times of interventional therapy were $2.00 \pm 1.17$ times (range, 1-5 times; median, 2). Radiotherapy was performed twice for a stage IV subject with progressive metastatic tumor at the lung and once for a stage III subject at the hepatoblastoma tissue. Liver transplantation was performed for 2 stage IV patients. In one of these subjects, a multiple space-occupying lesion was diagnosed. Chemotherapy was performed following hepatoblastoma relapse and partial remission (PR) was subsequently observed. For the other subject, high-dose chemotherapy and APBSCT was applied and the survival time for this subject was 6 months following liver transplantation.

Retrospective study on the prognoses. The follow-up lasted until August 31, 2014. The average time length of follow-up was 25.9 months (range, 1-94 months; median, 21 months). Complete remission (CR) was achieved in 52 subjects $(51.0 \%)$ and PR in 20 cases (19.6\%). The recurrence of hepatoblastoma was observed in 3 subjects $(2.9 \%)$ and 27 subjects succumbed to the disease $(26.5 \%)$. The effective rate (CR + PR) was $69.6 \%$. 
Table I. Categorization and clinical diagnoses for all 102 patients with pediatric hepatoblastoma.

\begin{tabular}{|c|c|c|}
\hline Criteria & $\begin{array}{l}\text { Number of } \\
\text { patients }\end{array}$ & Ratio (\%) \\
\hline \multicolumn{3}{|l|}{ COG stage } \\
\hline II & 4 & 4/102 (3.9) \\
\hline III & 48 & $48 / 102(47.1)$ \\
\hline IV & 50 & $50 / 102(49.0)$ \\
\hline \multicolumn{3}{|l|}{ Pathological type $^{\mathrm{a}}$} \\
\hline Epithelial & 52 & $52 / 91(57.1)$ \\
\hline Macrotubular & 11 & $11 / 91(12.1)$ \\
\hline Mixed & 28 & 28/91 (30.8) \\
\hline \multicolumn{3}{|l|}{ Primary site } \\
\hline Left lobe & 13 & $13 / 102(12.7)$ \\
\hline Right lobe & 47 & $47 / 102(46.1)$ \\
\hline Diffused & 42 & $42 / 102(41.2)$ \\
\hline \multicolumn{3}{|l|}{ Metastatic site ${ }^{\mathrm{b}}$} \\
\hline Lung & 37 & $37 / 49(75.5)$ \\
\hline $\begin{array}{l}\text { Superior vena cava tumor } \\
\text { emboli }\end{array}$ & 10 & $10 / 49(20.4)$ \\
\hline Intrahepatic metastasis & 17 & $17 / 49(34.7)$ \\
\hline Bone & 6 & $6 / 49(12.2)$ \\
\hline Atria & 2 & $2 / 49(4.1)$ \\
\hline Encephalic & 2 & $2 / 49(4.1)$ \\
\hline Colon and small intestine & 2 & $2 / 49(4.1)$ \\
\hline Pleura & 4 & $4 / 49(8.2)$ \\
\hline
\end{tabular}

aPathological typing was performed for 91 subjects. Surgical operation was not conducted for 8 subjects due to the accelerated malignancy of hepatoblastoma or for a further 3 subjects who were undergoing pre-surgical chemotherapy. ${ }^{b}$ Metastasis was observed in a total of 49 subjects, and multiple metastases were detected in several subjects. COG, Children's Oncology Group.

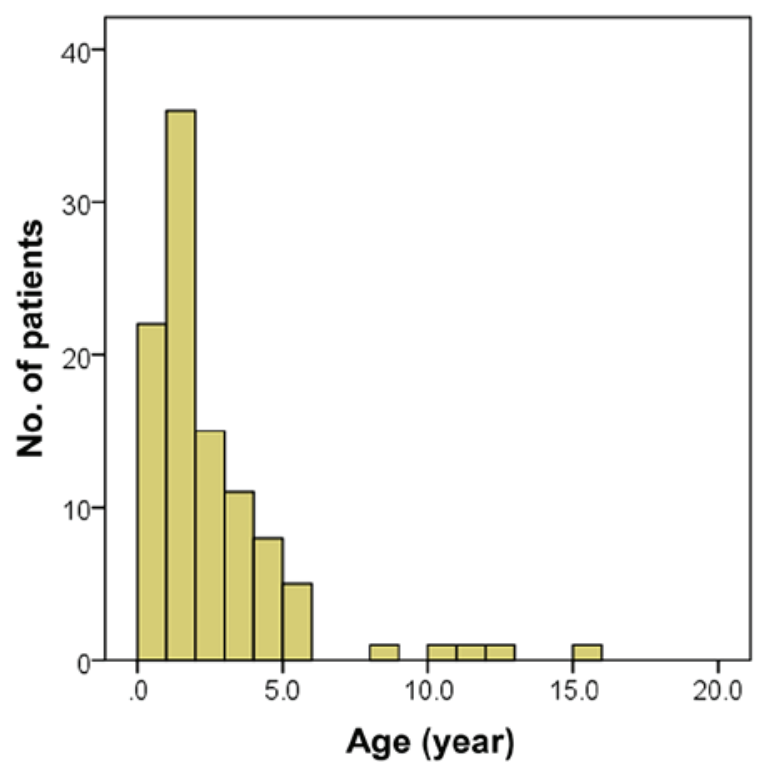

Figure 1. Age distribution of the 102 subjects. In total, $>30 \%$ of the patients were aged between 1 and 2 years.
Advanced hepatoblastoma is associated with a low survival rate. Total patient survival rates were $75.0,80.9$ and $20.2 \%$ for subjects with stage II, III and IV hepatoblastoma, respectively. The survival rate differed significantly among these different groups $\left(\mathrm{P}=0.015, \chi^{2}=8.359\right.$, log-rank test; Table II). The median survival time for stage IV subjects was 40 months [95\% confidence interval $(\mathrm{CI})=27.8-52.2$ months; Fig. 2].

Intrahepatic metastasis is associated with high mortality. In order to identify the major factor associated with the low survival rate of the stage IV subjects, the rate of hepatoblastoma metastasis among such patients was evaluated. At first, subjects with intrahepatic metastasis were assessed. According to the criteria adopted by COG (11), out of the 50 stage IV subjects, 16 were diagnosed with intrahepatic metastasis. The mortality rate of stage IV subjects with intrahepatic metastasis was significantly higher than that of stage IV patients without intrahepatic metastasis ( $\mathrm{P}=0.004$; Table III). In addition, the survival time was significantly shorter for stage IV subjects with intrahepatic metastasis compared with stage IV patients without intrahepatic metastasis $\left(\mathrm{P}=0.006, \chi^{2}=7.467\right.$, log-rank test; Table IV and Fig. 3).

Due to the existence of postoperative residual in stage IV subjects, the high mortality rate associated with intrahepatic metastasis implies that postoperative residual may affect the outcome of stage IV hepatoblastoma patients.

There is no difference in the survival rate between stage IV subjects with and without distant metastasis. Subsequently, the association between distant metastasis and survival rate of the 50 stage IV subjects was investigated. Distant metastasis was detected in 41 cases, and among them, 10 patients also had intrahepatic metastasis. A significant difference between the survival rates of stage IV subjects with distant metastasis and those without distant metastasis was detected $(\mathrm{P}=0.021$; Table V). However, according to the results of log-rank test and Kaplan-Meier survival analysis, the median survival time did not differ significantly between stage IV subjects with and without distant metastasis $\left(\mathrm{P}=0.063, \chi^{2}=3.462\right.$; Table VI and Fig. 4), suggesting that distant metastasis does not affect the outcome of stage IV hepatoblastoma.

High mortality rate for subjects experiencing relapse who abandon chemotherapy. Hepatoblastoma relapsed was observed in 45 out of the total 102 subjects. The median survival time for the 45 subjects was 12 months (range, 1-60 months). Hepatoblastoma relapse was detected in 1 stage II, 9 stage III and 35 stage IV patients. The stage II subject with relapsed hepatoblastoma experienced tumor progression to stage IV. Following two surgical operations and chemotherapy, the patient succumbed to the disease. Intrahepatic tumor recurrence was detected for all 9 stage III subjects with relapsed hepatoblastoma, implying that this caused the postoperative residual in relapse. Following treatment, 3 patients survived and 6 succumbed to the disease. For the 35 stage IV subjects with relapsed hepatoblastoma, 20 succumbed to the disease following chemotherapy.

The results of Fisher's exact test demonstrated that the relapse rate was significantly higher in stage IV subjects compared with stage III subjects $(\mathrm{P}=0.001$; Table VII). 
Table II. Survival rate of subjects with different stages of hepatoblastoma.

Outcomes

\begin{tabular}{lcccrr}
\cline { 2 - 4 } COG stage & Complete remission (\%) & Partial remission (\%) & Mortality (\%) & Relapse (\%) & Total (\%) \\
\hline $\mathrm{II}^{\mathrm{a}}$ & $3(75.0)$ & $0(0.0)$ & $1(25.0)$ & $0(0.0)$ & $4(100.0)$ \\
$\mathrm{III}$ & $32(66.7)$ & $10(20.8)$ & $6(12.5)$ & $0(0.0)$ & $48(100.0)$ \\
$\mathrm{IV}$ & $17(34.0)$ & $10(0.0)$ & $20(40.0)$ & $3(6.0)$ & $50(100.0)$ \\
Total & $52(51.0)$ & $20(19.6)$ & $27(26.5)$ & $3(2.9)$ & $102(100.0)$ \\
\hline
\end{tabular}

${ }^{\mathrm{a}}$ One patient within this group succumbed to the disease following surgical operation. COG, Children's Oncology Group.

Table III. Difference in mortality rates between stage IV subjects with and without intrahepatic metastasis.

\begin{tabular}{lccc}
\hline $\begin{array}{l}\text { Intrahepatic } \\
\text { metastasis }\end{array}$ & Alive $^{\mathrm{a}}$ & Succumbed & $\begin{array}{c}\text { P-value } \\
\text { (Fisher's exact test) }\end{array}$ \\
\hline Yes & 5 & 11 & $0.004^{\mathrm{b}}$ \\
No & 25 & 9 & \\
\hline
\end{tabular}

${ }^{a}$ Up to the end of the follow-up period. ${ }^{b} \mathrm{P}<0.01$.

Furthermore, the mortality rate for patients with relapsed hepatoblastoma was higher among stage III subjects compared with stage IV subjects ( $\mathrm{P}=0.041$; Table VIII).

A total of 27 out of the 45 subjects with relapsed hepatoblastoma succumbed to the disease. Among these 27 subjects, 20 had abandoned the chemotherapy treatment (1 stage II, 4 stage III and 15 stage IV subjects). Among the 25 relapsed patients that continued regular chemotherapy, only 7 succumbed to the disease following treatment. The difference in the mortality rate between subjects that continued chemotherapy and those that did not suggested that the mortality rate of patients with relapsed hepatoblastoma may be affected by chemotherapy.

No difference exists in the mortality rate among subjects with distinct pathological types of tumor. Definite tumor pathological types were attributed to 91 out of the 102 cases, including 52 epithelial, 28 mixed and 11 macrotrabecular. No significant difference in the mortality rate among patients with these different pathological types was detected (Table IX). However, subjects with different pathological types had different survival curves, indicating that the survival times of patients with different pathological types of tumor differed significantly $\left(\mathrm{P}=0.010, \chi^{2}=9.193\right.$, log-rank test; Fig. 5). This result implied that, although pathological typing may effectively demonstrate the degree of differentiation of the tumor tissue, it is not associated with disease prognosis.

\section{Discussion}

Pediatric hepatoblastoma is usually diagnosed in infants, particularly among those aged 1-2 years old (15). In the current study, $70 \%$ of subjects were $<3$ years old, which was

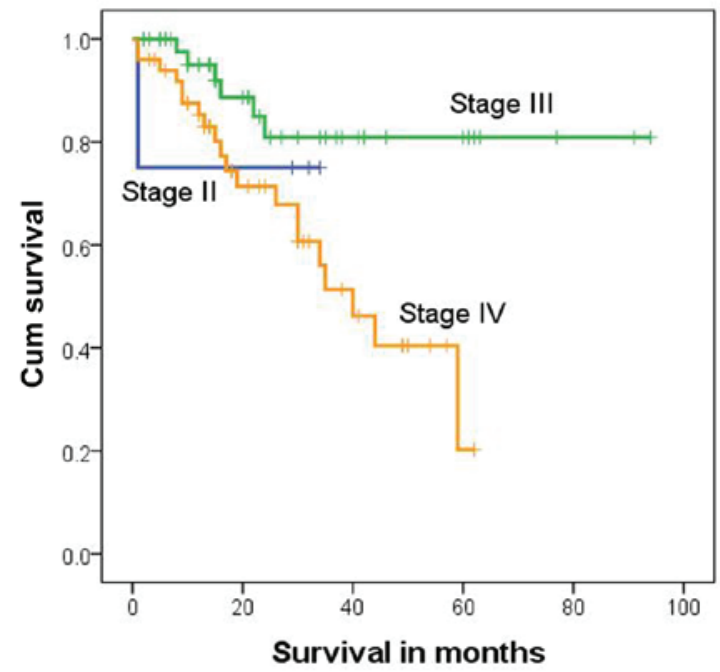

Figure 2. Survival analysis results of all stage IV subjects. Patients with stage IV have significant lower survival rate than patients with stage II and stage III $(\mathrm{P}=0.015)$. Cum, cumulative.

consistent with previous studies $(16,17)$. The majority of cases of pediatric hepatoblastoma begin with painless abdominal mass or diffused lesions (18). At first diagnosis, abdominal mass was observed in 74 of the subjects included in the current study and diffused hepatoblastoma was detected in 42 subjects at the primary site. It should be noted that one case was identified in the physical examination of the fetus prior to birth, which demonstrates the importance of performing physical examinations during pregnancy. Additionally, the disease history during pregnancy for the mothers of patients with pediatric hepatoblastoma should be emphasized, particularly for cases diagnosed $\leq 6$ months following birth.

The wildly applied treatment of hepatoblastoma in the current study included chemotherapy, radiotherapy, surgical resection and immunotherapy $(12,19,20)$. Liver transplantation and APBSCT with high-dose chemotherapy were performed on subjects at an advanced disease stage. The postoperative residual was difficult to remove solely using surgical operation due to the complicated structure of pediatric hepatoblastoma. The postoperative residual may be a cause of relapse, as suggested in the current study. However, due to the sensitivity of pediatric hepatoblastoma to chemotherapy, the tumor tissue may be completely resected following pre-surgical 
Table IV. Survival time of stage IV subjects with and without intrahepatic metastasis.

\begin{tabular}{lccrr}
\hline $\begin{array}{l}\text { Intrahepatic } \\
\text { metastasis }\end{array}$ & $\begin{array}{c}\text { Median survival } \\
\text { time, months }\end{array}$ & $\begin{array}{c}\text { 95\% confidence } \\
\text { interval }\end{array}$ & $\begin{array}{c}\text { 3-year } \\
\text { survival rate, \% }\end{array}$ & $\begin{array}{c}5 \text {-year } \\
\text { survival rate, \% }\end{array}$ \\
\hline Yes & 30 & $15.6-44.4$ & 17.8 & 8.9 \\
No & 59 & $37.5-80.5$ & 75.6 & 32.4 \\
\hline
\end{tabular}

Table V. Significant difference in survival rates between stage IV subjects with and without distant metastasis.

\begin{tabular}{lccc}
\hline $\begin{array}{l}\text { Distant } \\
\text { metastasis }\end{array}$ & Alive & Succubed & $\begin{array}{c}\text { P-value } \\
\text { (Fisher's exact test) }\end{array}$ \\
\hline Yes & 28 & 13 & $0.021^{\mathrm{a}}$ \\
No & 2 & 7 & \\
\hline
\end{tabular}

${ }^{\mathrm{a}} \mathrm{P}<0.05$.

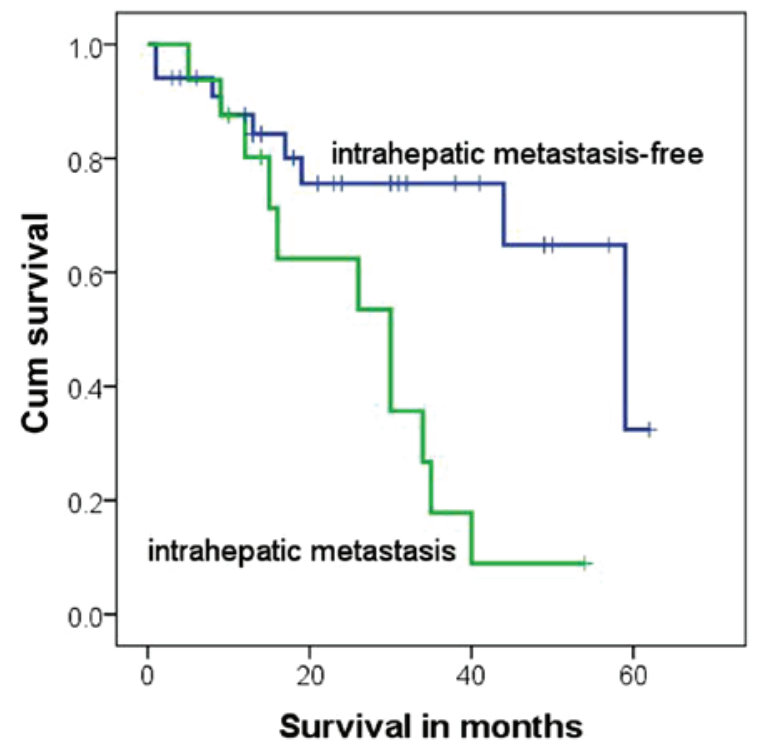

Figure 3. Survival analysis results of stage IV patients with or without intrahepatic metastasis. The survival time was significantly shorter for the stage IV subjects with intrahepatic metastasis compared with those stage IV cases without intrahepatic metastasis $(\mathrm{P}=0.006)$. Cum, cumulative.

chemotherapy and reduction of the primary tumor size. Additionally, post-surgical chemotherapy may effectively decrease the possibility of relapse and metastasis occurring due to cleaning up the postoperative residual, thus increasing the survival rate of subjects. For subjects with intact tumor capsule, intervenient chemotherapy was frequently applied to reduce the size of hepatoblastoma (21). A novel method of adjuvant chemotherapy has been suggested by SIOPEL to reduce tumor size and clear the postoperative residual (12). Furthermore, the COG has advised that this new adjuvant chemotherapy should be applied to treat stage III and IV subjects with vascular invasion or distant metastasis (13). Following adjuvant chemotherapy, a satisfactory outcome may be obtained. Therefore,

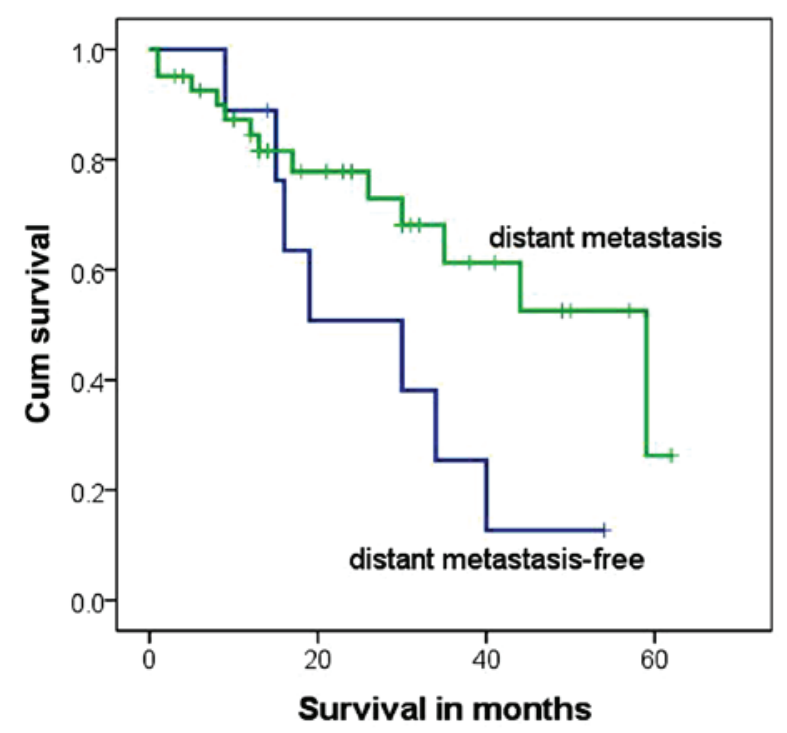

Figure 4. Survival analysis results of stage IV patients with or without distant metastasis. The median survival time was no significantly different between stage IV subjects with and without distant metastasis $(\mathrm{P}=0.063)$. Cum, cumulative.

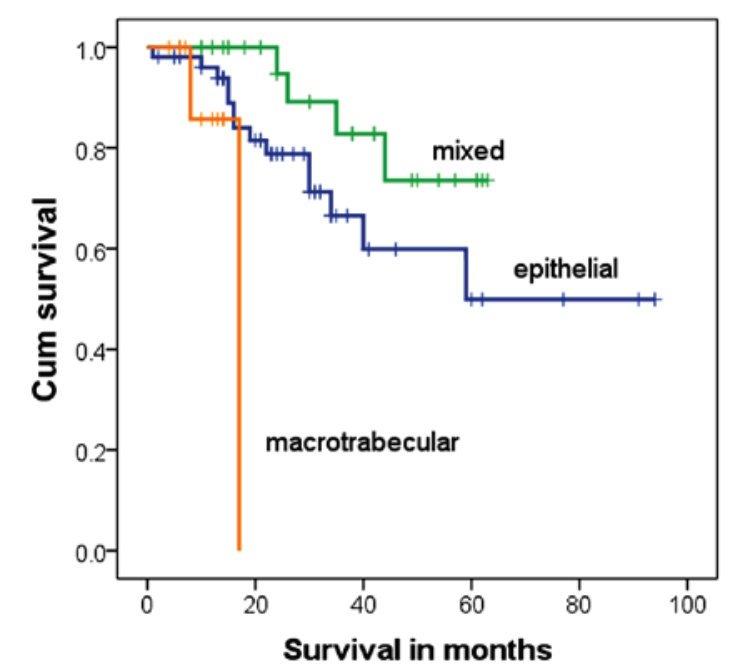

Figure 5. Survival analysis results of patients with different pathological types. Patients with different pathological types have different survival time. Patients with macrotrabecular type have significant shorter survival time compared with patients with mixed type and epithelial type $(\mathrm{P}=0.010)$. Cum, cumulative.

the combination of pre- and post-surgical chemotherapy and surgical operation may improve the prognosis of patients with pediatric hepatoblastoma, even for those with advanced stages of the disease. 
Table VI. Survival time of stage IV subjects with or without distant metastasis.

\begin{tabular}{lccccr}
\hline $\begin{array}{l}\text { Distant } \\
\text { metastasis }\end{array}$ & $\begin{array}{c}\text { Median survival } \\
\text { time, months }\end{array}$ & $\begin{array}{c}95 \% \\
\text { confidence interval }\end{array}$ & $\begin{array}{c}\text { 3-year } \\
\text { survival rate, } \%\end{array}$ & $\begin{array}{c}\text { 5-year } \\
\text { survival rate, \% }\end{array}$ & P-value \\
\hline Yes & 59 & $32.8-85.2$ & 61.3 & 26.3 & 0.063 \\
No & 30 & $11.4-48.6$ & 25.4 & 12.7 & \\
\hline
\end{tabular}

Table VII. Difference in relapse rate of hepatoblastoma between stage III and stage IV subjects.

\begin{tabular}{lccc}
\hline Relapse & Stage III & Stage IV & $\begin{array}{c}\text { P-value } \\
\text { (Fisher's exact test) }\end{array}$ \\
\hline Yes & 9 & $35^{\mathrm{a}}$ & $0.001^{\mathrm{b}}$ \\
No & 39 & 15 & \\
\hline
\end{tabular}

${ }^{\mathrm{a}}$ One relapsed tumor was detected in a stage II subject, who later progressed to stage IV hepatoblastoma. The subject was not counted in this table. ${ }^{\mathrm{b}} \mathrm{P}<0.01$.

Table VIII. Difference in the mortality rates of stage III and IV subjects following treatment for relapsed tumor.

P-value

\begin{tabular}{lccc} 
Stage & Alive & Succumbed & (Fisher's exact test) \\
\hline III & 3 & 6 & $0.041^{\mathrm{a}}$ \\
IV & 15 & 20 & \\
\hline
\end{tabular}

${ }^{\mathrm{a} P}<0.05$.

Table IX. Mortality rate of subjects with different pathological types.

\begin{tabular}{lccc}
\hline $\begin{array}{l}\text { Pathological } \\
\text { type }\end{array}$ & Alive & Succumbed & $\begin{array}{c}\text { P-value } \\
\text { (Fisher's exact test) }\end{array}$ \\
\hline Epithelial & 38 & 14 & 0.479 \\
Mixed & 24 & 4 & \\
Macrotrabecular & 9 & 2 & \\
\hline
\end{tabular}

Although hepatoblastoma can undoubtedly be identified using iconography analysis and serum alpha-fetoprotein examination, pre-surgical chemotherapy should be applied following pathological diagnosis $(20,22-25)$. If it is not feasible to conduct a liver puncture and confirm the existence of hepatoblastoma, one of the following criteria should be met to justify the application of pre-surgical chemotherapy: A significantly higher level of serum alpha-fetoprotein compared with normal controls; a tumor size that is too large for first resection or subject unendurable to surgical operation; diffused hepatoblastoma with calcification; distant metastasis; tumor hemorrhage; or stage III or IV hepatoblastoma (26).
In patients, $90 \%$ of the blood supply for hepatoblastoma flows through the hepatic artery (27). However, $\sim 75 \%$ of blood supplied to the healthy liver flows through the portal vein (28). Reducing the blood supply to hepatoblastoma without affecting blood supply to normal liver tissue may result in the selective necrosis of tumor cells. Furthermore, given the differences in blood supply, local interventional chemotherapy may be an ideal and specific measure of hepatoblastoma treatment.

In the present study, resection of primary hepatoblastoma was performed in 91 subjects. Radiofrequency ablation was applied to 4 subjects, including 3 with primary hepatoblastoma and 1 with a lung metastatic tumor. Additionally, minimally invasive surgery was conducted for the subject with a lung metastatic tumor. Systemic pre-surgical chemotherapy was performed in 72 subjects, and 86 subjects were treated with post-surgical chemotherapy. A total of 17 subjects were treated using the hepatic arterial chemoembolization method. CR was observed in 52 subjects and $P R$ in 20 . The effective rate $(C R+P R)$ was $69.6 \%$. This rate was slightly lower compared with that of a previous study. This inconsistency may have been caused by the high percentage of subjects with advanced hepatoblastoma (98 subjects were stages III and IV) and the abandonment of treatment following relapse of hepatoblastoma by 20 subjects in the current study.

It has previously been reported that the combination of liver transplantation and APBSCT with high-dose chemotherapy is effective in treating PRETEXT IV hepatoblastoma, hepatoblastoma invading the portal vein, micrometastatic hepatoblastoma and postoperative residual-induced relapse (19). Otte et al (29) demonstrated that 43 out of 49 hepatoblastoma subjects achieved tumor-free survival following liver transplantation. However, liver transplantation may be inappropriate for subjects with lung metastatic tumors or those unable to undergo surgical operation. For these subjects, APBSCT with high-dose chemotherapy may at least partially relieve the symptoms of the disease. In the current study, the stage IV subject with diffused primary hepatoblastoma relapsed following liver transplantation. Another stage IV subject achieved PR following liver transplantation; however, the patient only survived for 6 months. This suggests that, although liver transplantation partially relieves hepatoblastoma, it has little effect on the final outcome for subjects with advanced stages of the disease. The stage of hepatoblastoma, state of subjects and other issues should be taken into account prior to conducting liver transplantation.

A total of 27 subjects succumbed to the disease in the current study. All experienced a relapse of hepatoblastoma during treatment, indicating that tumor relapse may be the major cause of mortality among patients with hepatoblastoma. However, only 7 out of the 25 subjects who experienced 
relapse but underwent regular chemotherapy succumbed to the disease by the end of follow-up, suggesting the importance of chemotherapy in treating relapsed hepatoblastoma. The postoperative residual was regarded as a major cause of intrahepatic metastasis and tumor relapse. Distant metastasis and pathological type may have little effect on the outcome of hepatoblastoma. Therefore, in order to improve the survival rate of subjects with pediatric hepatoblastoma, efforts should be made to clear the postoperative residual and reduce the relapse rate.

\section{Acknowledgements}

The present study was supported by grants the Capital Health Research and Development of Special (Beijing, China; grant no. 2014-4-2054).

\section{References}

1. Devi LP, Kumar R, Handique A and Kumar M: Hepatoblastoma-a rare liver tumor with review of literature. J Gastrointest Cancer 45 (Suppl 1): 261-264, 2014.

2. Spyridakis I, Kepertis C, Lampropoulos V, Mouravas V and Filippopoulos A: Embryonal/Fetal subtype hepatoblastoma: A case report. J Clin Diagn Res 8: ND01-ND02, 2014.

3. Stiller CA, Pritchard J and Steliarova-Foucher E: Liver cancer in European children: Incidence and survival, 1978-1997. Report from the automated childhood cancer information system project. Eur J Cancer 42: 2115-2123, 2006.

4. de Fine Licht S, Schmidt LS, Rod NH, Schmiegelow K, Lähteenmäki PM, Kogner P, Träger C, Stokland T and Schüz J: Hepatoblastoma in the Nordic countries. Int J Cancer 131: E555-E561, 2012.

5. Gatta G, Ferrari A, Stiller CA, Pastore G, Bisogno G, Trama A and Capocaccia R; RARECARE Working Group: Embryonal cancers in Europe. Eur J Cancer 48: 1425-1433, 2012.

6. Aronson DC, Czauderna P, Maibach R, Perilongo G and Morland B: The treatment of hepatoblastoma: Its evolution and the current status as per the SIOPEL trials. J Indian Assoc Pediatr Surg 19: 201-207, 2014.

7. Evans AE, Land VJ, Newton WA, Randolph JG, Sather HN and Tefft M: Combination chemotherapy (vincristine, adriamycin, cyclophosphamide and 5-fluorouracil) in the treatment of children with malignant hepatoma. Cancer 50: 821-826, 1982.

8. Tiao GM, Bobey N, Allen S, Nieves N, Alonso M, Bucuvalas J, Wells R and Ryckman F: The current management of hepatoblastoma: A combination of chemotherapy, conventional resection and liver transplantation. J Pediatr 146: 204-211, 2005.

9. Pritchard J and Stringer M: Outcome and complications after resection of hepatoblastoma. J Pediatr Surg 39: 1744-1745, 2004.

10. Zhang Y, Zhang WL, Huang DS, Hong L, Wang YZ, Zhu X, Hu HM, Zhang PW, Yi Y and Han T: Clinical effectiveness of multimodality treatment on advanced pediatric hepatoblastoma. Eur Rev Med Pharmacol Sci 18: 1018-1026, 2014.

11. Trobaugh-Lotrario AD and Katzenstein HM: Chemotherapeutic approaches for newly diagnosed hepatoblastoma: Past, present and future strategies. Pediatr Blood Cancer 59: 809-812, 2012.

12. Czauderna P, Otte JB, Roebuck DJ, von Schweinitz D and Plaschkes J: Surgical treatment of hepatoblastoma in children. Pediatr Radiol 36: 187-191, 2006.
13. Malogolowkin MH, Katzenstein HM, Meyers RL, Krailo MD, Rowland JM, Haas J and Finegold MJ: Complete surgical resection is curative for children with hepatoblastoma with pure fetal histology: A report from the children's oncology group. J Clin Oncol 29: 3301-3306, 2011.

14. Schnater JM, Aronson DC, Plaschkes J, Perilongo G, Brown J, Otte JB, Brugieres L, Czauderna P, MacKinlay G and Vos A: Surgical view of the treatment of patients with hepatoblastoma: Results from the first prospective trial of the international society of pediatric oncology liver tumor study group. Cancer 94: 1111-1120, 2002

15. Yuan XJ, Wang HM, Jiang H, Tang MJ, Li ZL, Zou X, Fang YJ, Pan C, Tou JF, Zhang KR, et al: Multidisciplinary effort in treating children with hepatoblastoma in China. Cancer Lett 375: 39-46, 2016.

16. Matsunaga T, Sasaki F, Ohira M, Hashizume K, Hayashi A, Hayashi Y, Mugishima H and Ohnuma N; Japanese Study Group for Pediatric Liver Tumor: Analysis of treatment outcome for children with recurrent or metastatic hepatoblastoma. Pediatr Surg Int 19: 142-146, 2003.

17. Brugières L, Branchereau S and Laithier V: Paediatric malignant liver tumours. Bull Cancer 99: 219-228, 2012 (In French).

18. Honeyman JN and La Quaglia MP: Malignant liver tumors. Semin Pediatr Surg 21: 245-254, 2012.

19. Gupta AA, Gerstle JT, Ng V, Wong A, Fecteau A, Malogolowkin MH, Meyers RL, Grant D and Grant RM: Critical review of controversial issues in the management of advanced pediatric liver tumors. Pediatr Blood Cancer 56: 1013-1018, 2011.

20. von Schweinitz D: Management of liver tumors in childhood. Semin Pediatr Surg 15: 17-24, 2006.

21. Karski EE, Dvorak CC, Leung W, Miller W, Shaw PJ, Qayed M, Katsanis E and Feusner JH: Treatment of hepatoblastoma with high-dose chemotherapy and stem cell rescue: The pediatric blood and marrow transplant consortium experience and review of the literature. J Pediatr Hematol Oncol 36: 362-368, 2014.

22. Perilongo G, Maibach $\mathrm{R}$, Shafford E, Brugieres $\mathrm{L}$, Brock P, Morland B, de Camargo B, Zsiros J, Roebuck D, Zimmermann A,etal: Cisplatin versuscisplatin plusdoxorubicinfor standard-risk hepatoblastoma. N Engl J Med 361: 1662-1670, 2009.

23. Eicher C, Dewerth A, Ellerkamp V, Fuchs J, Schott S and Armeanu-Ebinger S: Effect of duplex drugs linking 2'-deoxy-5-fluorouridine (5-FdU) with 3'-C-ethynylcytidine (ECyd) on hepatoblastoma cell lines. Pediatr Surg Int 29: 121-127, 2013.

24. von Schweinitz D: Hepatoblastoma: Recent developments in research and treatment. Semin Pediatr Surg 21: 21-30, 2012.

25. Zsiros J,Maibach R, Shafford E, Brugieres L, Brock P, Czauderna P, Roebuck D, Childs M, Zimmermann A, Laithier V, et al: Successful treatment of childhood high-risk hepatoblastoma with dose-intensive multiagent chemotherapy and surgery: Final results of the SIOPEL-3HR study. J Clin Oncol 28: 2584-2590, 2010.

26. De Ioris M, Brugieres L, Zimmermann A, Keeling J, Brock P, Maibach R, Pritchard J, Shafford L, Zsiros J, Czaudzerna P and Perilongo G: Hepatoblastoma with a low serum alpha-fetoprotein level at diagnosis: The SIOPEL group experience. Eur J Cancer 44: 545-550, 2008.

27. Guérin F, Gauthier F, Martelli H, Fabre M, Baujard C, Franchi S and Branchereau S: Outcome of central hepatectomy for hepatoblastomas. J Pediatr Surg 45: 555-563, 2010.

28. Moreira RK, Chopp W and Washington MK: The concept of hepatic artery-bile duct parallelism in the diagnosis of ductopenia in liver biopsy samples. Am J Surg Pathol 35: 392-403, 2011.

29. Otte JB, Pritchard J, Aronson DC, Brown J, Czauderna P, Maibach R, Perilongo G, Shafford E and Plaschkes J; International Society of Pediatric Oncology (SIOP): Liver transplantation for hepatoblastoma: Results from the international society of pediatric oncology (SIOP) study SIOPEL-1 and review of the world experience. Pediatr Blood Cancer 42: 74-83, 2004. 